Philosophische Spaziergänge 


\section{Ludwig Giesz}

Philosophische Spaziergänge

Zwölf vorsichtige Antworten

auf die Frage,

wie man sich denn im Leben

einzurichten bätte

Mit einem Nachwort von Enno Rudolph

Verlag J.B. Metzler Stuttgart $\cdot$ Weimar 
Die Deutsche Bibliothek - CIP-Einheitsaufnahme

Ein Titeldatensatz für diese Publikation ist bei Der Deutschen Bibliothek erhältlich

ISBN 978-3-476-01879-3

ISBN 978-3-476-02826-6 (eBook)

DOI 10.1007/978-3-476-02826-6

Dieses Werk einschließlich aller seiner Teile ist urheberrechtlich geschützt. Jede Verwertung außerhalb der engen Grenzen des Urheberrechtsgesetzes ist ohne Zustimmung des Verlages unzulässig und strafbar. Das gilt insbesondere für Vervielfältigungen, Übersetzungen, Mikroverfilmungen und die Einspeicherung und Verarbeitung in elektronischen Systemen.

(C) 2001 Springer-Verlag GmbH Deutschland

Ursprünglich erschienen bei J.B. Metzlersche Verlagsbuchhandlung

und Carl Ernst Poeschel Verlag GmbH in Stuttgart 2001/1990

www.metzlerverlag.de

Info@metzler-verlag.de 


\section{Inhaltsverzeichnis}

\section{Philosophische Spaziergänge}

Epikur - Das Glück der Freundschaft

Seite 3

Seneca - Vom Glück der Resignation

Seite 20

Boethius - ... daß Wahrheit trösten kann

Seite 38

Erasmus - Von der Schwierigkeit, in heroischen Zeiten Kosmopolit zu sein

Seite 54

Francis Bacon - Der Kaufmann des Lichts

Seite 71

Nietzsche - Die große Gesundheit

Seite 86

\section{Von den Schwierigkeiten des Glücks}

Weder Engel, noch Tier. Zur »Anthroplogie« Pascals

Seite 105

Weder leugnen, noch glauben. Georg Christoph Lichtenberg und die Religion

Seite 128

Das Glück ist ein schwierig Ding. Bemerkungen zum Fall

Schopenhauer

Seite 149 


\section{Inhaltsverzeichnis}

\section{Nachspiel: Homo ridens}

Das Komische und die Philosophie

Seite 173

Sauer verdiente Weltbetrachtung. Aus Wilhelm Buschs Altersweisheit Seite 187

Entweder - Oder. Eine Hörfolge zum hundertsten Todestag von Sören Kierkegaard

Seite 200

Nachwort

Seite 223

\section{Editorische Notiz}

Seite 227 